\title{
Aerosol Radiative Forcing Derived from SeaWIFS-Retrieved Aerosol Optical Properties
}

\author{
Ming-Dah Chou \\ NASA/Goddard Space Flight Center \\ Greenbelt, Maryland 20771 \\ Pui-King Chan \\ Science Systems and Applications, Inc. \\ Lanham, Maryland 20706 \\ Menghua Wang \\ University of Maryland Baltimore County \\ NASA/Goddard Space Flight Center \\ Greenbelt, Maryland 20771
}

Submitted to Journal of the Atmospheric Sciences, Special GACP Issue

Corresponding Author:

Dr. Ming-Dah Chou

Code 913

NASA/Goddard Space Flight Center,

Greenbelt, Maryland 20771

e-mail: chou@climate.gsfc.nasa.gov 


\begin{abstract}
To understand climatic implications of aerosols over global oceans, the aerosol optical properties retrieved from the Sea-viewing Wide Field-of-view Sensor (SeaWiFS) are analyzed, and the effects of the aerosols on the Earth's radiation budgets (aerosol radiative forcing, ARF) are computed using a radiative transfer model. It is found that the distribution of the SeaWiFS-retrieved aerosol optical thickness is distinctively zonal. The maximum in the equatorial region coincides with the Intertropical Convergence Zone, and the maximum in the Southern Hemispheric high latitudes coincides with the region of prevailing westerlies. The minimum aerosol optical thickness is found in the subtropical high pressure regions, especially in the Southern Hemisphere. These zonal patterns clearly demonstrate the influence of atmospheric circulation on the oceanic aerosol distribution.
\end{abstract}

Over global oceans, aerosols reduce the annual-mean net downward solar flux by $5.4 \mathrm{~W} \mathrm{~m}^{-2}$ at the top of the atmosphere and by $6.1 \mathrm{~W} \mathrm{~m}^{-2}$ at the surface. The largest ARF is found in the tropical Atlantic, Arabian Sea, Bay of Bengal, the coastal regions of Southeast and East Asia, and the Southern Hemispheric high latitudes. During the period of the Indonesian big fires (September-December 1997), the cooing due to aerosols is $>15 \mathrm{~W} \mathrm{~m}^{-2}$ at the top of the atmosphere and $>30 \mathrm{~W} \mathrm{~m}^{-2}$ at the surface in the vicinity of the maritime continents. The atmosphere receives extra solar radiation by $>15 \mathrm{~W} \mathrm{~m}^{-2}$ over a large area. These large changes in radiative fluxes are expected to have enhanced the atmospheric stability, weakened the atmospheric circulation, and augmented the drought condition during that period. It would be very instructive to simulate the regional climatic 
The model-calculated clear-sky solar flux at the top of the atmosphere is compared with that derived from the Clouds and the Earth's Radiant Energy System (CERES). The net downward solar flux of CERES is systematically larger than the model calculations by $\sim 3 \mathrm{~W} \mathrm{~m}^{-2}$. In the equatorial region, the CERES-derived net downward solar flux is even larger than the model calculations without including aerosols. It is possible that the CERES incorrectly identified regions of high humidity and high aerosol cencentration as being cloud contaminated and, hence, overestimated the clear-sky net downward solar flux. 


\section{Introduction}

Aerosols directly affect the heat budgets of the Earth by reflecting and absorbing solar radiation. The lifetime of aerosols is short and the temporal and spatial variations are large. As a result, information on long-term and global distributions of aerosols is lacking, and the climatic impact of aerosols is not well understood.

Satellite remote sensing of aerosols over land is difficult because the reflectivity of aerosols is usually smaller than the reflectivity of land surface. Over oceans, the surface reflectivity is small and aerosol optical properties can be estimated much more reliably than that over land. Distributions of aerosols over global oceans have been derived from various satellite radiance measurements. For example, Husar et al. (1997) retrieved the aerosol optical thickness from the radiance measured in the $0.63-\mu \mathrm{m}$ channel of the NOAA Advanced Very High Resolution Radiometer (AVHRR). Michchenko et al. (1999) applied a two-channel retrieval algorithm to the AVHRR measurements and derived both the optical thickness and the Angstrom exponent, which provides information on the spectral variation of the optical thickness. Deuze et al. (1999) retrieved the aerosol optical thickness and the Angstrom exponent from the radiances and polarization measured in the $0.670-\mu \mathrm{m}$ and the $0.865-\mu \mathrm{m}$ channels of the POLDER instrument on the Japanese Advanced Earth Satellite System (ADEOS). Recently, Rajeev et al. (2000) retrieved the aerosol optical thickness over Arabian Sea, Bay of Bengal, and the Indian Ocean using the radiance measured in Channel $1(0.63 \mu \mathrm{m})$ of the AVHRR. The retrieval used an aerosol model constructed from the aerosol chemical, microphysical and optical properties measured at an island station during the Indian Ocean Experiment (INDOEX). In addition to satellite retrievals, global distributions of aerosol have also 
been simulated using models. Chin et al. (2000) derived the global distributions of optical properties of five aerosol types using a chemistry-aerosol-transport model driven by assimilated atmospheric temperature, humidity, and cloud fields. The products include not only the optical thickness but also the single-scattering albedo and asymmetry factor, all of which are important for computing the radiative effect of aerosols (or aerosol radiative forcing, ARF).

The National Aeronautics and Space Administration (NASA) launched the Seaviewing Wide Field-of-view Sensor (SeaWiFS) satellite on 1 August, 1997 to measure global ocean color and to retrieve ocean bio-optical properties (Hooker et al., 1992). The retrieved aerosol optical thickness over global oceans is a by-product of SeaWiFS. The aerosol data are available starting from September 1997. The SeaWiFS is a polar orbiting satellite with an equatorial crossing at local noon, and the temporal resolution of the retrieved aerosol optical thickness is once a day. It has a high spatial resolution of $1 \mathrm{~km}$.

In this study, we conduct radiative transfer calculations to assess the radiative forcing of aerosols retrieved from the SeaWiFS radiance measurements. The radiative transfer model used for calculating ARF and the source of data used for input to the radiation model are described in Section 2 . Section 3 analyzes the distribution of the SeaWiFS-retrieved aerosol over global oceans and its relation to atmospheric circulation. Section 4 presents the results of model-calculated ARF at TOA, in the atmosphere, and at the surface. Comparisons of the model-calculated clear-sky solar flux at the top of the atmosphere (TOA) with satellite retrievals are given in Section 5. Conclusion of this work is given in Section 6. 


\section{Radiative transfer model and data source}

The effects of aeorsols on the solar radiation (or aerosol radiative forcing, ARF) at TOA, in the atmopshere, and at the surface are calculated using the radiation model of Chou and Suarez (1999). Calculations of clear-sky solar fluxes include the absorption of solar radiation by ozone, water vapor, $\mathrm{CO}_{2}$, and $\mathrm{O}_{2}$, scattering due to gases (Rayleigh scattering), and the absorption and scattering due to aerosols. Interactions among gas absorption, Rayleigh scattering, aerosol scattering and absorption, and surface reflection are explicitly included using the $\delta$-Eddington approximation. The solar spectrum is divided into the UV/visible region $(0.175-0.7 \mu \mathrm{m})$ and the infrared region $(0.7-10 \mu \mathrm{m})$. The UV and visible region is further divided into 8 bands, and the IR region is divided into 3 bands. Single values of the ozone absorption coefficient, Rayleigh scattering coefficient, and aerosol optical properties (optical thickness, single-scattering albedo, asymmetry factor) are used for each band. The absorption in the IR due to water vapor is computed using the $k$-distribution method, where $k$ is the absorption coefficient. Ten values of $k$ are used in each of the three IR bands, whereas a single value of $k$ is applied to computing the water vapor absorption in the photosynthetically active (PAR) region from 0.4 to $0.7 \mu \mathrm{m}$. Aerosol optical properties are not parameterized but are specified.

Data input to the radiation model for clear-sky flux calculations include vertical profiles of temperature, humidity, and ozone, the aerosol optical properties, and the albedo of the ocean surface. The temperature fields are taken from the National Centers for Environmental Prediction/National Center for Atmospheric Research (NCEP/NCAR) reanalysis (Kalnay et al., 1996). The column water vapor is taken from the Special Sensor Microwave/Imager (SSMI) retrievals of Wentz (1994). The column ozone amounts are 
taken from the Total Ozone Mapping Spectrometer (TOMS) retrievals (McPeters et al., 1998), which are climatological monthly-mean values. To justify the use of climatological monthly ozone amount, we have conducted model sensitivity studies. Model calculations show that fluxes at the TOA and the surface are not sensitive to the ozone amount. The daily mean surface flux in the tropics changes by $<0.5 \mathrm{~W} / \mathrm{m}^{-2}$ when the column ozone amount changes from $0.25(\mathrm{~cm}-\mathrm{atm})_{\text {sp }}$ to $0.32(\mathrm{~cm}-\mathrm{atm})_{\text {spp }}$. The former is a typical ozone amount of equatorial regions, and the latter is typical of subtropical regions. The shape of vertical profiles of water vapor and ozone also has little effects on the absorption of solar radiation. These profiles are assumed to follow that of a typical mid-latitude summer atmosphere by scaling the column water vapor and ozone amounts, so that the column amounts are the same as that of the SSMI- and TOMS-retrieved values. The albedo of the ocean surface is fixed at 0.05 , which is assumed to be the mean albedo averaged over solar zenith angles and over both direct and diffuse downward solar fluxes at the surface.

The SeaWiFS algorithm uses the radiances measured at $0.765-\mu \mathrm{m}$ and $0.865-\mu \mathrm{m}$ channels to select a most appropriate aerosol model. The aerosol optical thickness is then retrieved from the radiance of the $0.865-\mu \mathrm{m}$ channel (Wang, et al., 2000). The spectral variation of the aerosol optical thickness is a function of the particle size. For the SeaWiFS maritime aerosol model, the optical thickness relative to that at $0.865 \mu \mathrm{m}$ is approximated by

$$
\tau_{\lambda}=a \lambda^{b}
$$


where $\tau$ is the optical thickness, $\lambda$ is the wavelength. The parameter $a$ is a function of $\lambda$, ranging from 0.086 to 2.2 for the 11 spectral bands used in the solar radiation model. The parameter $b$ depends weakly on $\lambda$ and is set to 0.22 .

The asymmetry factor, $g$, varies slightly with aerosol models and is fixed at 0.786 in computing ARF, which is typical for maritime aerosols. The single-scattering albedo affects significantly the ARF, especially at the surface. Over the vast oceanic regions, most of the aerosols are maritime in nature, and sulfuric aerosols can be assumed as typical over oceanic regions. For maritime sulfuric aerosols, the absorption is weak, and we fix the single-scattering albedo, $\omega_{0}$, at 0.9955 in the model calculations. For aerosols in regions of active tropical forest fires and in the windward side of major deserts, the optical thickness is large. The absorption of solar radiation by these aerosols is strong. The magnitude of $\omega_{0}$ is in the range of 0.88-0.9 (Gras et al., 1999; Podgorny et al., 2000; Tegen et al., 1996). Due to lack of detailed information on the absorption property of oceanic aerosols, we assume that $\omega_{0}=0.9955$ and $g=0.786$ for $\tau_{\mathrm{a}}<0.18$ to represent maritime aerosols and $\omega_{0}=0.9$ and $g=0.69$ for $\tau_{\mathrm{a}}>0.3$ to represent dusts from deserts and smoke from forest fires. For $0.18<\tau_{\mathrm{a}}<0.3, \omega_{\mathrm{o}}$ and $g$ are interpolated linearly with $\tau_{\mathrm{a}}$.

Aerosols are assumed to be evenly distributed between the surface and the $800-\mathrm{mb}$ level. Model calculations show that the ARF is not sensitive to the vertical extend of aerosols. When the upper boundary of the aerosol layer is changed from $800 \mathrm{mb}$ to 900 mb, the ARF at TOA changes by $<5 \%$.

The solar fluxes are computed at $30-$ min intervals. The solar zenith angle is computed as a function of local time, day, and latitude. Since SeaWiFS retrieves aerosol optical thickness only once a day, we make an assumption that the SeaWiFS-retrieved 
aerosol optical thickness at the time of the satellite measurements represents the value of a whole day. The ARF's presented in the study are mean values averaged over both day and night.

To understand the aerosol distribution over global oceans, we also have computed the global distribution of the divergence of wind. The wind field of the NCEP/NCAR reanalysis is used in this study. Finally, the clear-sky TOA flux derived from the Clouds and the Earth's Radiant Energy System (CERES) (Wielicki et al., 1996) is used for the comparison with the model-calculated solar flux at TOA.

3. Distribution of aerosol optical thickness over global oceans

The SeaWiFS-retrieved aerosol optical thickness at $0.865 \mu \mathrm{m}, \tau_{\mathrm{a}}$, is shown in Fig. 1 for October 1997, January 1998, April 1998, and July 1998. To relate the aerosol distribution to the atmospheric circulation, the divergence of winds derived from the NCEP/NCAR reanalysis is also shown in the figure for the same months. The most striking feature is that the aerosol distribution is largely zonal. High optical thickness is found in tropical oceans and at high latitutes in the Southern Hemisphere (SH). Low optical thickness is found in the subtropics of both hemispheres. This distribution pattern coincides with atmospheric circulation; high in convergence regions and low in divergence regions. The large aerosol optical thickness in the tropical Atlantic is found in all seasons. It is a well acknowledged feature related primarily to the Sahara desert dusts and secondarily to African forest fires. The prevailing easterly winds bring the aerosols across the Atlantic to the east coast of the Central and South Americas. 
The maximum in equatorial oceans was not previously acknowledged. The question arises concerning the source of the aerosols, especially over the central equatorial Pacific. It is possible that the maximum over equatorial oceans is caused by the convergence of aerosols from subtropical regions in a way similar to the convergence of water vapor. Strong trade winds in the tropics could produce a substantial amount of sea salt and carry the aerosols to the equatorial region. The types of aerosols in the equatorial region could provide critical information on the source of aerosols. Unfortunately, little information is available.

In January 1998, a narrow band of minimum $\tau_{\mathrm{a}}$ is found near the equator over Pacific, Atlantic and Indian Oceans. It is consistent with the Intertropical Convergence Zone (ITCZ), which is also shown in the panel on the side-hand-side of the same figure. According to the NCEP/NCAR reanalysis, this ITCZ is also the zone of maximum precipitation (not shown in the figure). It is likely that the minimum is related to the removal of aerosols by rain. Other months do not show this feature. It is interesting to note that normally one would concern that the aerosol optical thickness might be overestimated in the ITCZ because of the difficulty in detecting thin or remnants of clouds in a satellite-field-of view. Apparently, this is not a problem for the SeaWiFS aerosol retrieval for the month of January 1998.

The large value of $\tau_{\mathrm{a}}$ in the Arabian Sea and the Bay of Bengal is found in April and July, 1998, which is believed to be contributed from fossil fuel combustion and windblown dusts. The July maximum of $\tau_{a}$ in the Arabian Sea is also evident in the retrievals using the AVHRR radiance measurements (Husar et al., 1997; Mishchenko et al., 1999). In aerosol retrievals using the AVHRR measurements, Rajeev et al. (2000) found that, in 
January 1998, the optical thickness in the Arabian Sea and the Bay of Bengal is high. This feature is not found in the SeaWiFS retrieval. Part of the reason for this discrepancy might be due to the limit imposed in the SeaWiFS-retrieval algorithm that no retrievals are made for the $\tau_{\mathrm{a}}>0.45$ at $0.865 \mu \mathrm{m}$.

During the period September-November 1997, there were big forest fires in Indonesia. The period of the big Indonesian fires coincides with the 1997-1998 El Nino when the convection center in the maritime continents shifted eastward to the central Equatorial Pacific, and Indonesia was under the influence of subsiding air, which augmented the forest fires. The large value of $\tau_{\mathrm{a}}$ is shown clearly in the SeaWiFS retrievals (top-left panel), which extends from the Maritime continents westward to the equatorial Indian Ocean.

In the SH, the maximum at high latitudes, centered at $60^{\circ} \mathrm{S}$, is related to a large amount of sea salt and maritime sulfuric aerosols generated by strong prevailing westerlies. This maximum aerosol band is also shown in the study of Chin et al. (2000) using a chemical model coupled to the atmospheric circulation simulated by the Data Assimilation Office of NASA/Goddard Space Flight Center. The minimum in the subtropical zone, centered at $30^{\circ} \mathrm{S}$, is also evident in Husar et al. (1997) and Mishchenko et al. (1999).

Figure 2 shows the histogram of the SeaWiFS-retrieved aerosol optical thickness over global oceans for the year 1998. Both mean and median are 0.105 at $0.865 \mu \mathrm{m}$. The region with $\tau_{1}>0.25$ is very small.

4. Aerosol radiative forcing 
The aerosol radiative forcing (ARF) at TOA and the surface averaged over the year 1998 are shown in Fig. 3. The ARF is first calculated for each day and then averaged over the year. Large aerosol cooling of the ocean-atmosphere system (upper panel) exceeding $6 \mathrm{~W} \mathrm{~m}^{-2}$ is found in the tropical Atlantic, central equatorial Pacific, southern hemispheric high latitudes, and the coastal regions extending from East Africa, Arabian Sea, Bay of Bengal, Southeast Asia, to East Asia. In the eastern tropical Atlantic, the maximum cooling exceeds $8 \mathrm{~W} \mathrm{~m}^{-2}$ due to Sahara dust and forest fires. The minimum cooling is located in the subtropics, especially in the $\mathrm{SH}$ where the cooling is $<4 \mathrm{~W} \mathrm{~m}^{-2}$.

The lower panel of Fig. 3 shows the annual-mean ARF at the surface. The distribution of ARF at the surface follows closely the ARF at TOA. In the tropical Atlantic and the Arabian Sea, the forcing at the surface is much larger than that at TOA, with a maximum cooling of $\sim 15 \mathrm{~W} \mathrm{~m}^{-2}$. By taking the difference between the forcing at TOA and the surface, it follows that aerosols in these regions enhance the solar heating of the atmosphere by $\sim 4 \mathrm{~W} \mathrm{~m}^{-2}$. It is noted that the large surface ARF in the tropical Atlantic and the Arabian Sea occurs primarily in the summer months of May-September, 1998.

Table 1 shows the aerosol radiative forcing averaged over oceans in January, April, July, and October, and the whole year of 1998. The seasonal change in ARF is large. The maximum and minimum of the monthly-mean ARF differ by $\sim 40 \%$ in the Northern Hemisphere $(\mathrm{NH})$ and $-55 \%$ in the SH. The larger seasonal variation in the SH ARF is due to the larger fractional oceanic coverage at high latitudes in the SH than in the $\mathrm{NH}$; the seasonal variation of the incoming solar radiation at TOA is larger at high latitudes than at low latitudes. Averaged over global oceans, the annual mean ARF is $-5.4 \mathrm{~W} \mathrm{~m}^{-2}$ at 
TOA and $-6.1 \mathrm{~W} \mathrm{~m}^{-2}$ at the surface. Aerosols enhance the atmospheric solar heating by $0.7 \mathrm{~W} \mathrm{~m}^{-2}$

As can be expected, the latitudinal distribution of ARF changes significantly with seasons due to the change in the noontime solar zenith angle. The upper panel of Fig. 4 shows that, averaged over oceanic area of respective latitude zones, the cooling at TOA in the summer hemisphere is $6-8 \mathrm{~W} \mathrm{~m}^{-2}$, but decreases significantly in the winter hemisphere. Averaged over a year, the two hemispheres are rather symmetric (lower panel). Maximum cooling occurs at high latitudes and in the equatorial region. As can be seen from the difference between the forcing at TOA and the surface, aerosols significantly enhance the solar heating of the atmosphere in the tropics, with a maximum of $\sim 2 \mathrm{~W} \mathrm{~m}^{-2}$ at $10^{\circ} \mathrm{N}$.

During the 1997-1998 El Nino period, the big Indonesian fires produced a large amount of aerosols. Figure 5 shows that in October 1997 the ARF in the neighborhood of the maritime continents reaches $-10 \mathrm{~W} / \mathrm{m}^{2}$ at TOA and $-25 \mathrm{~W} / \mathrm{m}^{2}$ at the surface, with an enhanced atmospheric solar heating of $15 \mathrm{~W} / \mathrm{m}^{2}$. This large change in the atmospheric and surface radiation budgets over a large area is expected to have a significant impact on the regional and seasonal climate. Generally, the reduced surface heating due to aerosols will reduce the transfer of water vapor and latent heat to the atmosphere. The atmospheric boundary layer will be more stable and the atmospheric circulation is expected to be less rigorous. In a GCM study of the climatic implication of enhanced cloud absorption of solar radiation, Kielh et al. (1996) found that the extra solar heating of the upper troposphere due to cloud absorption enhanced the stability of the atmosphere, weakened the Hadley circulation, and reduced surface latent heat flux. Since the big 1997-1998 
Indonesian forest burning lasted for several months and covered a large area, it might have a similar effect as the excess cloud absorption of solar radiation in decelerating the hydrological cycle and in strengthening the drought of the region associated with the El Nino.

The largest ARF occurs in the eastern portion of the tropical Atlantic and spread westward to the east cost of Central America and northern South America. High ARF is found through the whole year. The large aerosol forcing is expected to have a significant effect on cloud dynamics, the atmospheric stability, and the atmospheric circulation in the tropical Atlantic. In the Arabian Sea and the Indian Ocean, large aerosol forcing is found in the Spring and Summer (from March through September). As a part of the INDOEX, Podgorny et al. (2000) studied the aerosol radiative effect based on data collected at an island station in the Indian Ocean. They found that during the period February-March 1998, the ARF is $-4 \mathrm{~W} \mathrm{~m}^{-2}$ at TOA, $-16 \mathrm{~W} \mathrm{~m}^{-2}$ at the surface, and $+12 \mathrm{~W} \mathrm{~m}^{-2}$ in the atmosphere. These numbers are consistent with our caluculations based on the SeaWiFSretrieved aerosols, which are $-4 \mathrm{~W} \mathrm{~m}^{-2}$ at TOA, $-12 \mathrm{~W} \mathrm{~m}^{-2}$ at the surface, and $+8 \mathrm{~W} \mathrm{~m}^{-2}$ in the atmosphere.

\section{Comparison with CERES clear-sky solar flux}

Errors are expected to occur in the model-calculated ARF due to uncertainties in the aerosol optical thickness, single-scattering albedo, and asymmtry factor, as well as the radiative transfer parameterization. It is desirable to compare model calculations with satellite-retrieved fluxes at TOA. The clear-sky TOA fluxes derived from the CERES on the Tropical Rainfall Measuring Mission (TRMM) covers a period of eight month, from 
January to August 1998. The data has a temporal resolution of 1 month and a spatial resolution of $2.5^{\circ} \times 2.5^{\circ}$ latitude-longitude. The TRMM satellite is a polar-orbiting satellite with a low inclination angle. The CERES only retrieves TOA fluxes at middle and low latitudes between $40^{\circ} \mathrm{S}$ and $40^{\circ} \mathrm{N}$. In Figure 6, we compare the model-calculated clearsky solar flux with that of CERES. The upper panel shows the difference in the clear-sky net downward solar fluxes at TOA, $F_{\text {net }}$, between the CERES and the model calculations (CERES minus model) for January 1998. Except in isolated regions off the west coast of Australia and South Africa, the CERES-derived $F_{n e t}$ is generally larger than model calculations. The maximum difference is found in a band south of the equatorial with a magnitude larger than $9 \mathrm{~W} \mathrm{~m}^{-2}$. Averaged over the ocean between $40^{\circ} \mathrm{S}$ and $40^{\circ} \mathrm{N}$, the difference is $+3.5 \mathrm{~W} \mathrm{~m}^{-2}$.

The lower panel of the figure shows the difference in $F_{n e t}$ between the CERES retrieval and the model calculation without including aerosols. The difference is generally negative. Averaged over the ocean between $40^{\circ} \mathrm{S}$ and $40^{\circ} \mathrm{N}$, the difference is $-1.6 \mathrm{~W} \mathrm{~m}{ }^{-2}$. Since the CERES derives $F_{n e t}$ from satellite-measured radiances, the effect of aerosols in included. Therefore, the difference shown in the lower panel of the figure can be interpreted as the direct ARF at TOA. The negative values over most of the ocean are expected. However, the difference is positive in the equatorial region, which implies a warming effect of aerosols. In the absence of evidence of a large amount of strong absorbing aerosols in the equatorial region, this positive difference is not expected. The band of this positive ARF coincides with the ITCZ shown in Fig. 1. The ITCZ is a region of high humidity and cloudiness. It coincides well with the band of high aerosol optical thickness, also shown in Fig 1. It is possible that the CERES might have identified clear- 
sky regions of high humidity and high aerosol content as regions contaminated by clouds. If this is the case, the CERES might have identified only those regions with relatively dry and low aerosol content as free of cloud contamination. The magnitude of $F_{n e t}$ is a maximum in those dry and clean regions, which leads to an overestimation of $F_{n e l}$. It is noted that the ARF is a small number resulting from the difference between two large quantities of $F_{n e t}$. A small error in either $F_{\text {net }}$ could potentially introduce a large error in the estimated ARF. The positive ARF in the equatorial region as shown in the figure is an indication of this problem. Not only the error is large, but also the sign is reversed.

\section{Conclusions}

The direct aerosol radiative forcing (ARF) over global oceans is calculated using the solar radiation model of Chou and Suarez (1999) and the aerosol optical properties retrieved by the SeaWiFS. Other data input to the radiation model include the column water vapor retrieved from SSMI radiance measurements, the climatological monthly mean column ozone amount retrieved from TOMS, and the temperature field from the NCEP/NCAR reanalysis.

The aerosol distribution is largely zonal. Th large-scale distribution coincides well with the convergence of winds. Large aerosol optical thickness, $\tau_{2}$, is found in the equatorial region, southern hemispheric high latitudes, Arabian Sea, Bay of Bengal, and the coastal region of the Southeast and East Asia. Minimum $\tau_{\mathbf{a}}$ is found in the subtropical divergence zones, especially in the SH. The large $\tau_{\mathbb{a}}$ found in the tropical Atlantic persists through most of the year. The prevailing trade winds carry the desert dusts across the Atlantic from Africa to the coast of Central and South Americas. The influence of winds 
on the aerosol distribution is in resemblance of humidity distribution. Aerosol optical thickness is high in convergence zones and low in divergence zones. Averaged over a year, the mean and median of the SeaWiFS-retrieved $\tau_{\mathrm{a}}$ at $0.865 \mu \mathrm{m}$ are both 0.105 .

Over global oceans, the annual mean ARF is $-5.4 \mathrm{~W} \mathrm{~m}^{-2}$ at TOA and $-6.1 \mathrm{~W} \mathrm{~m}^{-2}$ at the surface. The seasonal variation of the ARF is small for global oceans, but it is large for individual hemispheres. The TOA ARF increases by $40 \%$ from October to April in the Northern Hemisphere and by $50 \%$ from October to April in the Southern Hemisphere. The clear-sky TOA ARF of $-5.4 \mathrm{~W} \mathrm{~m}^{-2}$ is equivalent to a cooling of $\sim 2.5 \mathrm{~W} \mathrm{~m}^{-2}$ when the fractional area of clear-sky regions is taken into consideration. This magnitude of the aerosol cooling is comparable to the warming due to a doubling of the atmospheric $\mathrm{CO}_{2}$, which is $\sim 4 \mathrm{~W} \mathrm{~m}^{-2}$.

The ARF during the 1997 Indonesian big forest fires is very large. Over a large area in the vicinity of the maritime continents, the cooling due to aerosols in the period September-November, 1997 , is $>10 \mathrm{~W} \mathrm{~m}^{-2}$ at TOA and $>25 \mathrm{~W} \mathrm{~m}^{-2}$ at the surface. Aerosols enhance the solar heating of the atmosphere by $\sim 15 \mathrm{~W} \mathrm{~m}^{-2}$. The 1997 Indonesian big forest fires occurred during the 1997-1998 El Nino event, when the maritime continents was under the influence of subsiding air mass and was in drought conditions. The enhanced atmospheric heating and the surface cooling caused by the aerosols of biomass burning could have the effects of increasing atmospheric stability, weakening the atmospheric circulation, and augmenting the drought condition. It would be interesting to study the interactions between the ARF of the biomass burning and the dynamics during an El Nino event using climate model simulations. 
Acknowledgments. This work was supported by the Radiation Research Program (MDC and PKC) and the SIMBIOS Porject (MHW), NASA/Office of Earth Science. The aerosol data were produced and distributed, respectively, by the SeaWiFS Project and the Distributed Active Archive Center at the NASA Goddarad Space Flight Center. The winds and temperature fields were taken from the NCEP/NCAR reanalysis archive. The SSM/I-retrieved total precipitable water were produced by Remote Sensing Systems sponsored, in part, by NASA and NOAA (Principal Investigator: Frank Wentz). The CERES data were obtained from the NASA Langley Research Center EOSDIS Distributed Active Archive Center. 


\section{References}

Chou, M.-D., and M. J. Suraez, 1999: A shortwave radiation parameterization for atmospheric studies. 15, NASA Tech Memo-104606. pp40.

Chin, M., P. Ginoux, M.-D. Chou, S. Kinne, C. Weave, 2000: The GOCART model study of aerosol composition and radiative forcing.

Deuze, J. L., M. Herman, P. Goloub, D. Tanre, and A. Marchand, 1999: Characterization of Aerosols over ocean from POLDER/ADEOS-1. Geophy. Res. Letter, 26, 14211424.

Gras, J. L., J. B. Jensen, K. Okada, M. Ikegami, Y. Zaizen, and Y. Makino, 1999: Some optical properties of smoke aerosol in Indonesia and tropical Australia. Geophy. Res. Letter, 26, 1393-1396.

Hooker, S. B., W. E. Esaias, G. C. Feldman, W. W. Gregg, and C. R. McClain, 1992: An overview of SeaWiFS and Ocean Color, NASA Tech Memo. 104566, Vol. 1 of SeaWiFS Technical Report Series, NASA Goddard Space Flight Center, Greenbelt, Maryland, 24 pp.

Husar, R. B., J. M. Prospero, and L. L. Stowe, 1997: Characterization of tropospheric aerosols over the oceans with the NOAA advanced very high resolution radiometer optical thickness operational product. J. Geophy. Res., 102, 16889-16909.

Kalnay, E., M. Kanamitsu, R. Kistler, W. Collins, D. Deaven, L. Gandin, M. Iredell, S. Saha, G. White, J. Woollen, Y. Zhu, M. Chelliah, W. Ebisuzake, W. Higgins, J. Janowiak, K. C. Mo., C. Ropelewski, J. Wang, A. Leetmaa, R. Reynolds, R. Jenne, and D. Joseph, 1996: The NCEP/NCAR 40-year reanalysis project. Bull. Amer. Meteorol. Soc., 77, 437-471. 
Kiehl, J. T., J. J. Hack, M. H. Zhang, and R. D. Cess, 1995: Sensitivity of a GCM climate to enhanced shortwave cloud absorption. J. Climate, 8, 2200-2212.

McPeters, R.D., P.K. Bhartia, A.J. Krueger, J.R. Herman, C.G. Wellemeyer, C.J. Seftor, G.Jaross, O. Torres, L. Moy, G. Labow, W. Byerly, S.L. Taylor, T. Swissler, R.P. Cebula, 1998. Earth Probe Total Ozone Mapping Spectrometer (TOMS) Data Products User's Guide. NASA Reference Publication 1998-206895.

Mishchenko, M. I., I. V. Geogdzhayev, B. Cairns, W. B. Rossow, and A. A. Lacis, 1999: Aerosol retrievals over the ocean by use of channels 1 and 2 AVHRR data: sensitivity analysis and preliminary results. Appl. Opt., 38, 7325-7341.

Podgorny, I. A., W. Conant, V. Ramanathan, and K. Satheesh, 2000: Aerosol modulation of atmospheric and surface solar heating over the tropical Indian Ocean. Tellus, 52B, 947-958.

Rajeev, K., V. Ramanathan, and J. Meywerk, 2000: Regional aerosol distribution and its long-range transport over the Indian Ocean. . J. Geophy. Res., 105, 2029-2043.

Tegen, I., A. A. Lacis, and I. Fung, 1996: The influence on climate forcing of mineral aerosols from disturbed soils. Nature, 380, 419-422.

Wang, M., S. Bailey, and C. R. McClain, 2000: SeaWiFS provides Unique global aerosol optical property data. EOS, Amer. Geophy. Union, 81, 197-202.

Wentz, F. J., 1994: User's Manual SSM/I -2 Geophysical Tapes. Tech. Rep. 070194, 20 pp. [Available from Remote Sensing Systems, Santa Rosa, CA.]

Wielicki, B. A., B. R. Barkstrom, E. F. Harrison, R. B. Lee III, G. L. Smith, and J. E. Cooper, 1996: Clouds and the Earth's Radiant Energy System (CERES): An earth observing system experiment. Bull. Amer. Meteor. Soc., 77, 853-868. 
Table 1. Aerosol radiative forcing over oceans. Units: $\mathrm{W} \mathrm{m}^{-2}$.

\begin{tabular}{lccccc}
\hline & Oct 97 & Jan 98 & Apr 98 & Jul 98 & Annual \\
\hline & \multicolumn{5}{c}{ TOA } \\
& & & & \\
\cline { 2 - 6 } & & & & & \\
NH & -4.8 & -5.2 & -6.7 & -6.1 & -5.7 \\
SH & -6.1 & -6.6 & -4.2 & -3.9 & -5.2 \\
Global & -5.5 & -6.0 & -5.2 & -4.9 & -5.4 \\
& & & Surface & & \\
& & & & & \\
NH & -5.2 & -5.7 & -7.8 & -7.4 & -6.5 \\
SH & -7.0 & -7.2 & -4.4 & -4.1 & -5.7 \\
Global & -6.2 & -6.6 & -5.8 & -5.6 & -6.1 \\
\hline
\end{tabular}




\section{Figure Captions}

Figure 1. The SeaWiFS-retrieved aerosol optical thickness at $0.865 \mu \mathrm{m}$ (left panels) and the divergence of winds derived from the NCEPNCAR reanalysis (right panels). Units of the wind divergence are $s^{-1}$.

Figure 2. Distribution of the SeaWiFS-retrieved aerosol optical thickness at $0.865 \mu \mathrm{m}$ for the year 1998 over global oceans.

Figure 3. The model-calculated aerosol radiative forcing at the top of the atmosphere (upper panel) and at the surface (lower panel) averaged over the year 1998. Units are $\mathrm{W} \mathrm{m}^{-2}$.

Figure 4. Latitudinal distributions of the aerosol radiative forcing (ARF) at the top of the atmosphere (TOA) in January and July 1998 (upper panel), and latitudinal distributions of the annual-mean ARF at TOA and the surface for the year 1998 (lower panel).

Figure 5. Aerosol radiative forcing at the top of the atmosphere, at the surface, and in the atmosphere for the month of October 1997, when there were big forest fires in Indonesia. Units are $\mathrm{W} \mathrm{m}^{-2}$.

Figure 6. Differences between the CERES-retrieved clear-sky net downward solar flux at TOA and that calculated using a radiation model with aerosols (upper panel) and without aerosols (lower panel). Units are $\mathrm{W} \mathrm{m}^{\cdot 2}$. 

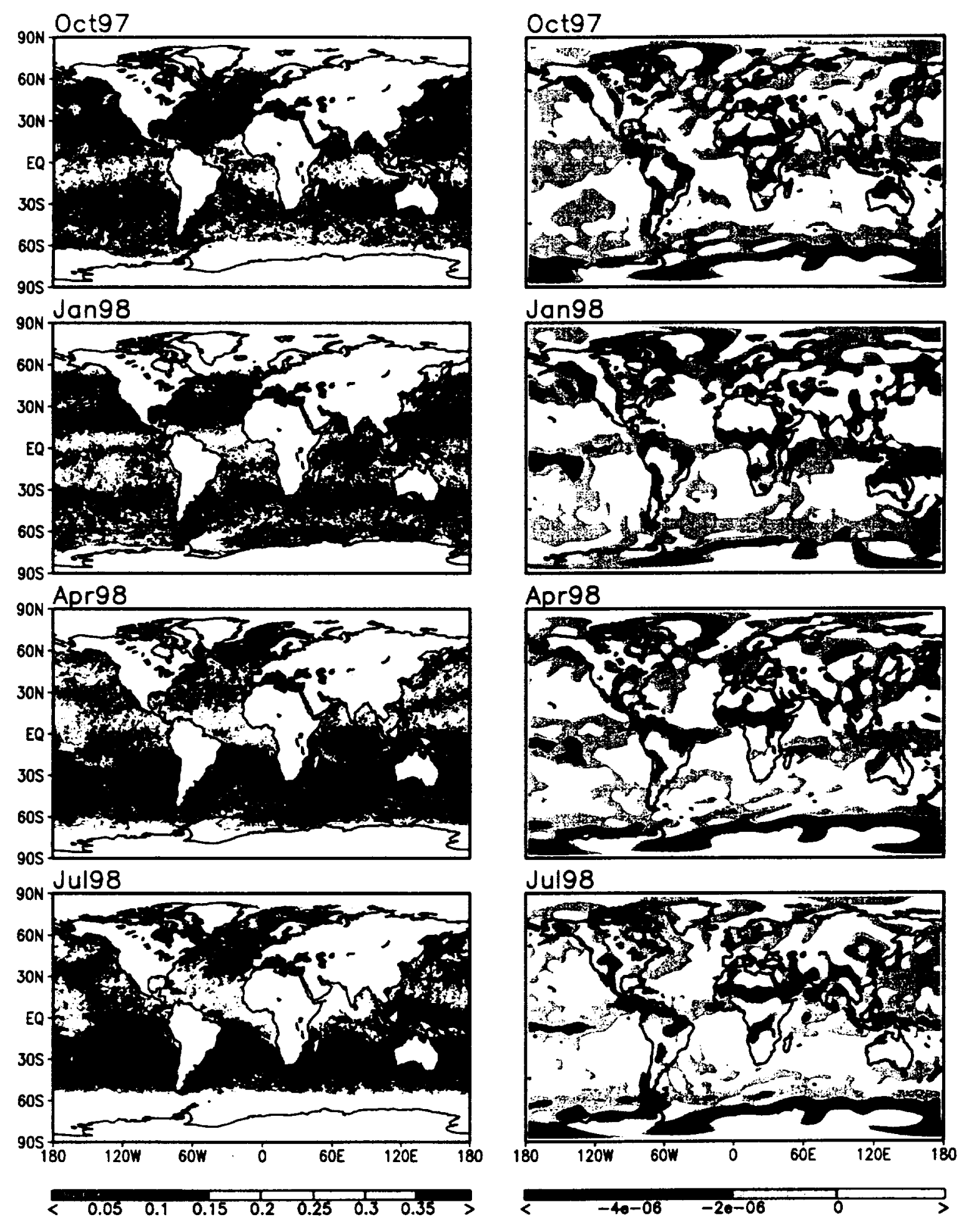


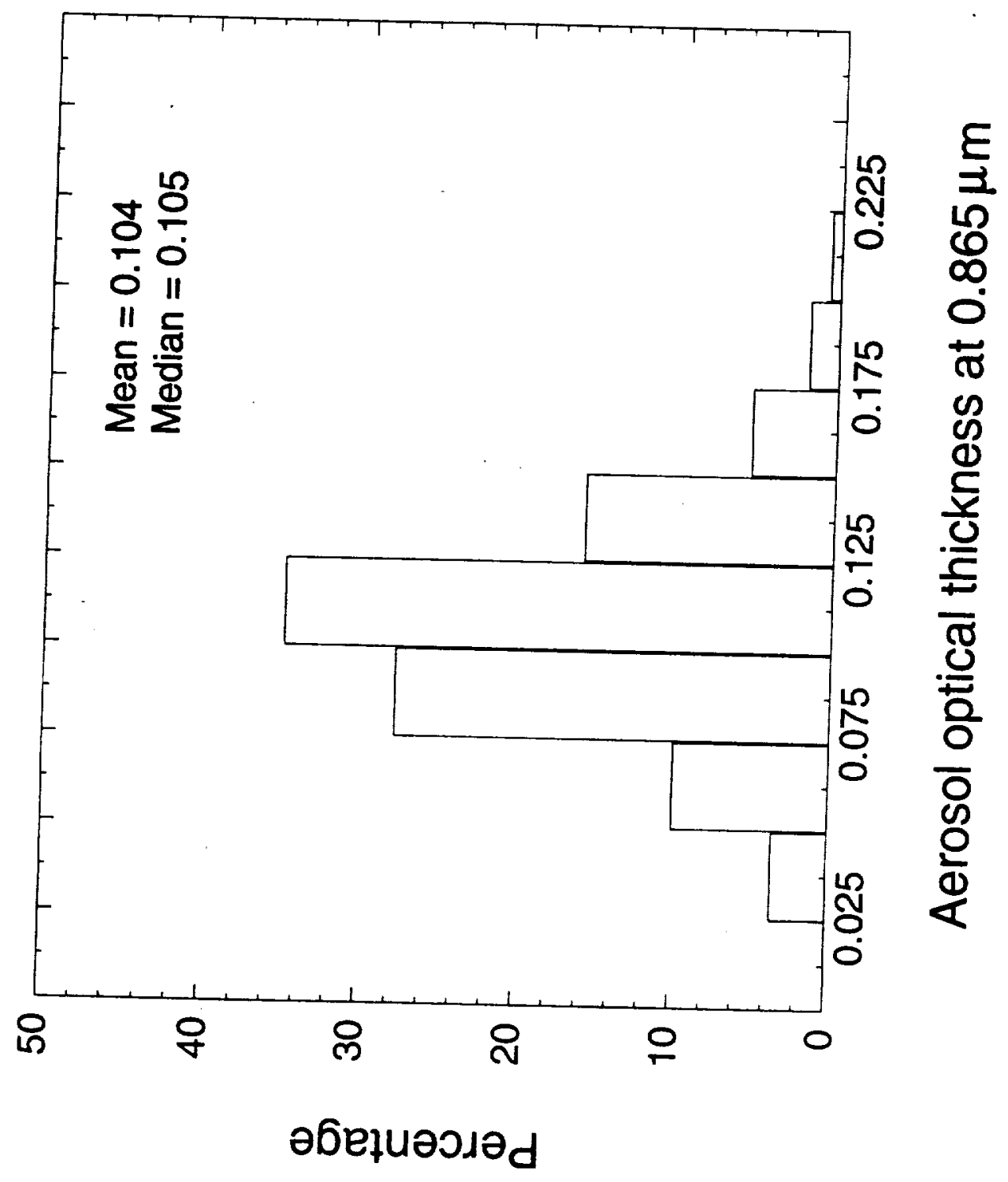

$N$ ن 


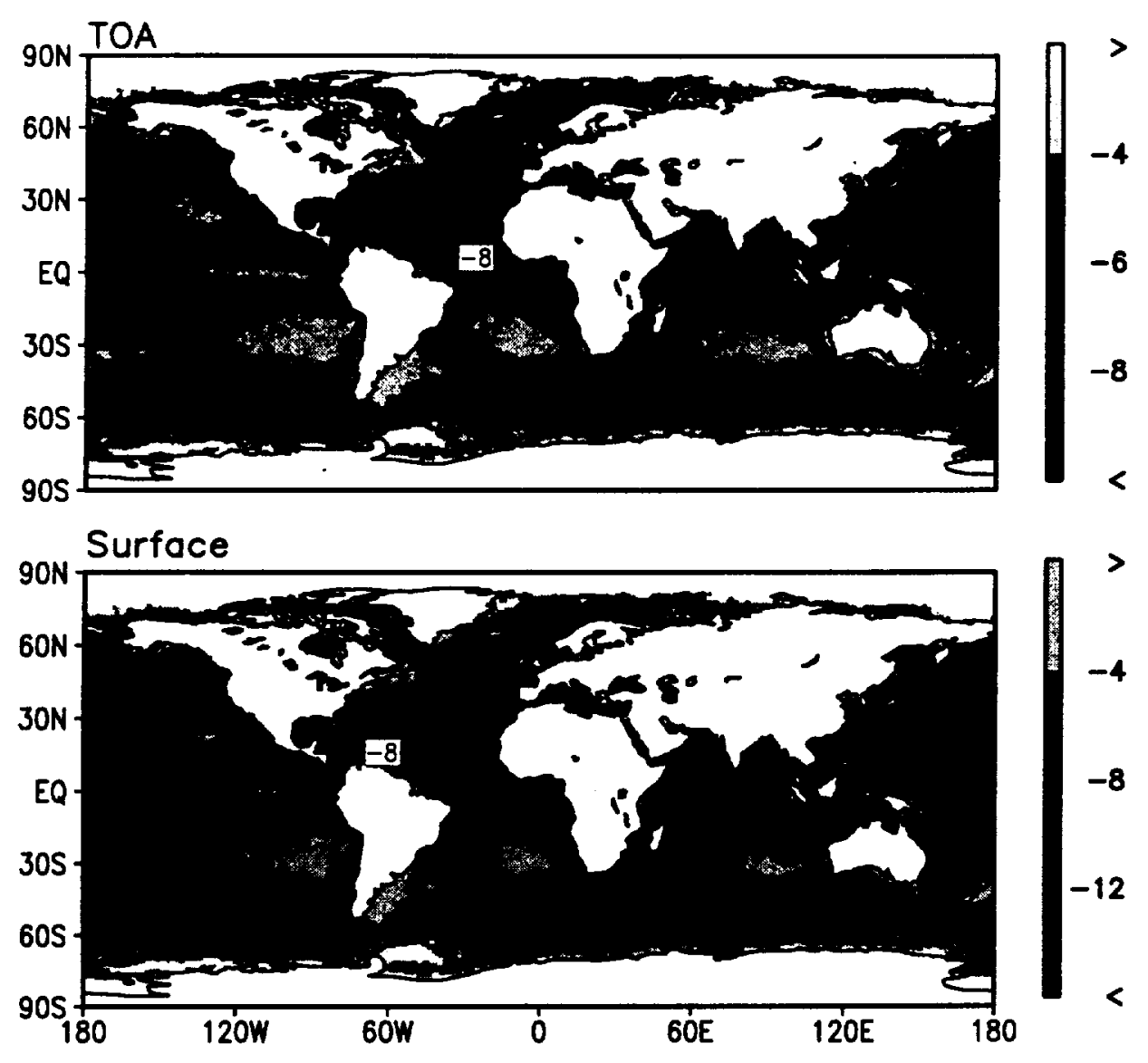



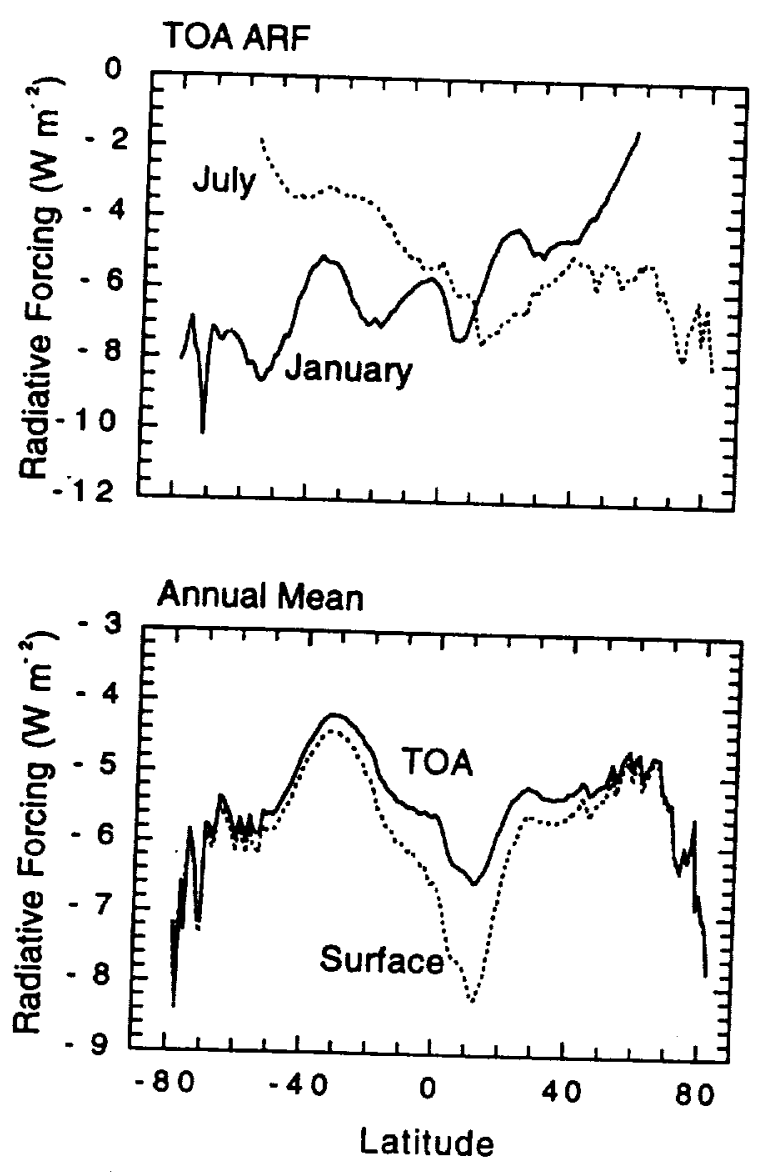

Fig 4 


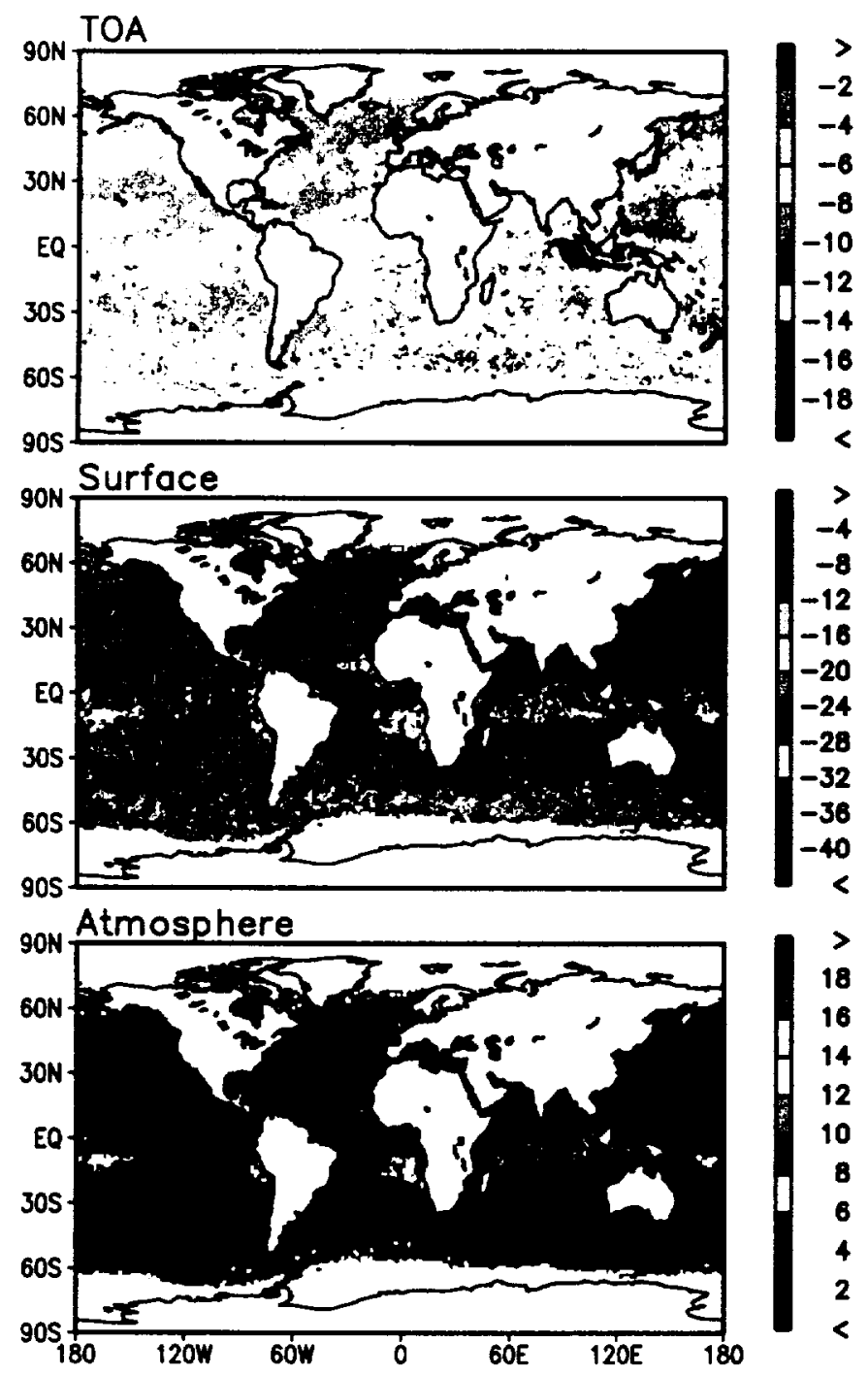




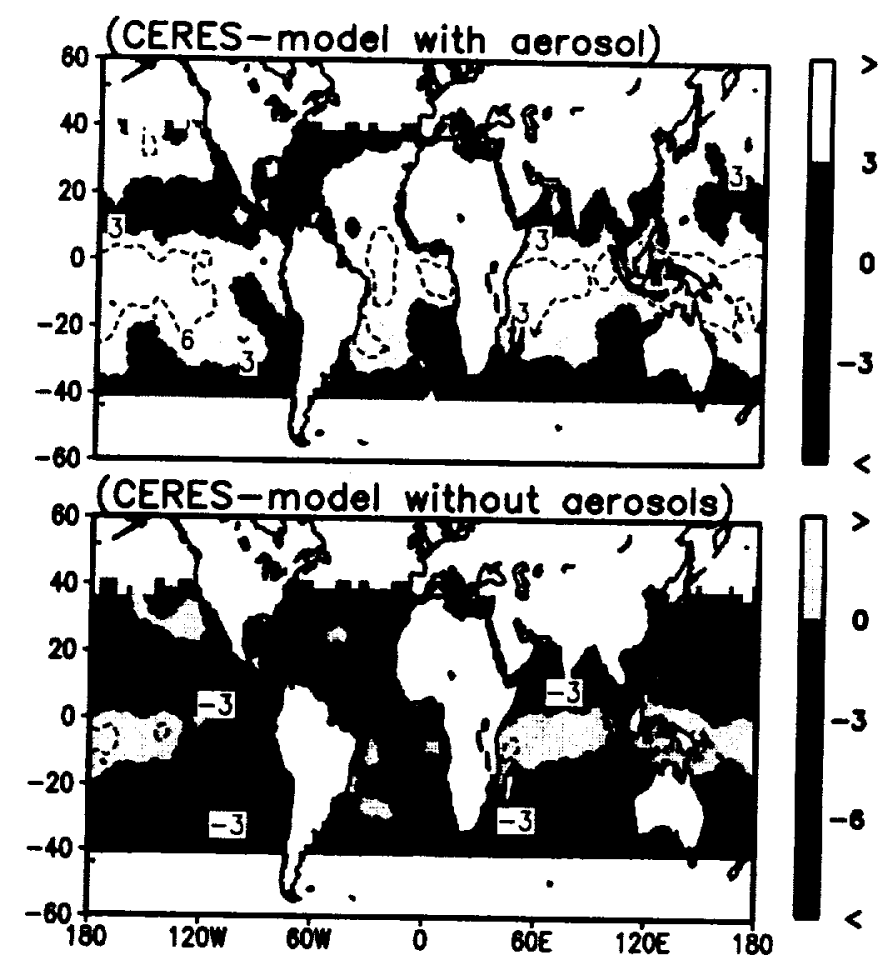

